\title{
Crisis y fragilidad financiera griega bajo la hipótesis de inestabilidad de Minsky
}

\author{
Amparo Alejandra Reyes Escobar / Carlos Antonio Rozo Bernal \\ Universidad Autónoma Metropolitana - Xochimilco - México
}

Recibido: 10 de febrero de 2020 / Aceptado: 1 de mayo de 2020

\begin{abstract}
Resumen
Grecia aún no ha encontrado el camino hacia su recuperación desde que su economía se contrajera año tras año desde el 2008. Se argumenta en este artículo que el factor central de este resultado fue la dinámica de financiación de los países más involucrados en el endeudamiento griego, que fue considerablemente mayor y que influyó más negativamente sobre la economía griega que el deficiente y dispendioso manejo fiscal en el que pudieron incurrir diferentes gobiernos. El ímpetu mostrado por los servicios financieros no correspondió a la debilidad del sector real, pues el endeudamiento y los flujos financieros fueron utilizados sin restricción alguna para satisfacer los intereses de los acreedores. En este trabajo se realiza un análisis de los canales que fueron alimentando la deuda griega en el contexto propuesto por Minsky (1992) de inestabilidad financiera, que tiene lugar cuando una economía transita desde la estabilidad financiera hacia un escenario de inestabilidad soportado en dos variables determinantes: los altos y exagerados intereses del servicio de la deuda y el tipo de agentes poseedores de los activos de deuda. Los intereses del servicio de la deuda contraída por el Gobierno desde su incorporación a la zona euro junto al fuerte impulso de la financiación provocaron que la deuda se convirtiese en una bola de nieve gigante, mientras que el cambio en los poseedores de deuda impidió que el Gobierno pudiera cumplir con las estrictas y onerosas reformas gubernamentales y macroeconómicas, que repercutieron directamente sobre la capacidad de pago de los Gobiernos griegos y que provocaron resultados negativos sobre el bienestar de la sociedad.
\end{abstract}

Palabras clave

Grecia / Crisis financiera / Financiación / Deuda externa.

\section{Greek crisis and financial fragility in Minsky's instability hypothesis}

\begin{abstract}
Greece has still not found its way back while its economy has been deteriorating year after year since 2008. It is argued in this article that the central factor of this outcome was the dynamics of financing in the countries most involved in Greek indebtedness that was considerably greater and had a more detrimental influence on the Greek economy than poor fiscal management that different governments could incur. The impetus displayed by financial services did not correspond to the weakness of the real sector which occurs when borrowing and financial flows are used without restriction to meet the interests of creditors. In this work an analysis of the channels that fueled Greek debt is carried out in the context proposed by Minsky where an economy moves from financial stability to a scenario of instability supported in two determining variables: high and exaggerated interest on debt service and the type of agents holding debt assets. The debt-service interest incurred by the government since joining the eurozone and the impetus for financing caused the debt to have a giant snowball effect while the change in debt holders forced the government to comply with strict and onerous government and macroeconomic reforms that directly impacted the ability of Greek governments to pay with negative results on the well-being of society.
\end{abstract}

\section{Keywords}

Greece / Financial crisis / Financialization / External debt.

JEL Codes: F32, F34, F36, F41.

\footnotetext{
*Correspondencia autor: rozo@correo.xoc.uam.mx
} 


\section{Introducción}

Grecia, un país pequeño con solo el 2,6\% del producto interno bruto (PIB) de la zona euro, vio alterada su frágil situación económica con la Gran Recesión (GR), resultado de la intensificación del proceso de financiación al que fue sometida cuando ingresó en la zona euro y que, sin remedio, sentó las condiciones para que su economía se contrajera año tras año desde 2008, provocando una reducción del $25 \%$ de su PIB en el año 2018.

Para entender esta dinámica -resultado de la insostenibilidad de una situación de fuerte endeudamiento-, existen diferentes puntos de vista tanto con respecto a los factores que provocan situaciones de crisis como a los motivos por los cuales no es posible salir de ellas. Autores como, entre otros, Galbraith (2007), Kindleberger y Aliber (2011), Minsky (1992), Rozo (2011), Temin (1991) o Varoufakis y Tserkesis (2014), achacan la situación de crisis a diversos factores -sucesos previos con causas exógenas y endógenas- que contribuyen a generar desequilibrios macroeconómicos. En este caso, como argumentan Varoufakis y Tserkesis $(2014$, p. 52), un factor clave que es preciso tener en cuenta es que "la dinámica de financiación en los países más involucrados en el endeudamiento griego ha sido considerablemente mayor y nocivamente más influyente sobre la economía griega que los efectos internos de la más lenta financiación acontecida en la economía local”.

El comportamiento de la actividad financiera es difícil de explicar, en función de su relación con la economía de la producción, como consecuencia de la capacidad de los bancos para diferenciar la actividad financiera de la actividad productiva (Drucker, 1986; Lapavitsas, 2009; Menkhoff y Tolksdorf, 2001; Rozo, 2003). Resulta paradójico que el fuerte impulso de los servicios financieros no se corresponda con la debilidad del sector real cuando el endeudamiento y las inversiones financieras se utilizan sin restricciones para multiplicar los ingresos y las ganancias bancarias. Más aún, la lógica de que la innovación financiera puede eliminar el riesgo ha creado un problema de agencia debido, por un lado, a dejar a los prestamistas originales sin incentivos para evitar malos préstamos y, por otro, a promover incentivos para encadenar malos y buenos créditos. La tesis de que todos los riesgos pueden ser calculados favoreció un comportamiento especulativo, que contribuyó a que los bancos comerciales se convirtieran en actores centrales de la crisis financiera que paralizaba la actividad productiva, tal y como señaló Minsky.

La insistencia de los Gobiernos del norte europeo -principalmente el alemán- en que los problemas financieros de los países del sur de Europa fueron causados por un deficiente manejo fiscal ${ }^{1}$ se contradice con el hecho de que la deuda se disparara a niveles fuera de control debido a la crisis causada por las hipotecas basura de Estados Unidos, intensificándose la oposición contra el keynesianismo para favorecer la pauta de la austeridad fiscal (Blyth, 2014). La vulnerabilidad de los bancos ante la dinámica de la financiación obligó a los gobiernos a embarcarse en rescates obligatorios, convirtiendo estos programas de ayuda europea en préstamos para recapitalizar a los bancos, ya que, como demostraron Schularick y Taylor (2014, p. 156), las crisis de deuda soberana son casi siempre consecuencia del desplome de una desaforada expansión de la actividad crediticia.

Este contexto permite formular a modo de hipótesis que el paso de una situación de estabilidad financiera a otra de inestabilidad puede ser explicado por el crecimiento exacerbado de la deuda griega a partir del año 2008, deuda que era la consecuencia de los exagerados niveles de intereses que se sumaban año tras año al capital de la deuda y no simplemente debida al gasto excesivo del Gobierno, como pretendieron justificar las autoridades de los países del norte de Europa. Para explicar estos resultados, consecuencia de la financiación de la economía griega, este trabajo se divide en cinco apartados, además de esta introducción. En el primero se presenta la "Hipótesis de Inestabilidad Financiera" (HIF) propuesta por Minsky como marco teórico que sirve para entender el problema del endeudamiento, mientras en el segundo apartado se examinan aspectos generales económicos de la economía griega que dan cuenta de su problema de endeudamiento. En el tercer apartado se detalla la situa-

\footnotetext{
${ }^{1}$ No se debe pasar por alto el beneficio para Alemania de un tipo de cambio infravalorado que promueve sus exportaciones dentro de la zona.
} 
ción provocada en la macroeconomía griega por el endeudamiento en el período 1995-2018, en una lógica de estática comparativa de los parámetros exógenos que determinaron el endeudamiento. En los apartados cuarto y quinto se revisan las consecuencias de los diferentes momentos de endeudamiento propuestos por Minsky. Por último, se presentan conclusiones y comentarios.

\section{La hipótesis de inestabilidad financiera}

Para comprender la problemática económico-financiera de la economía de Grecia se recurre a la HIF propuesta por Hyman Minsky (1992), quien modeliza una economía capitalista que posee activos reales con precios elevados y con un sistema financiero complejo y sofisticado que, por su evolución, puede ser interpretado como un proceso de desacoplamiento financiero o de financiación de la economía capitalista. El modelo presentado por Minsky explica cómo ocurren las crisis financieras y su repercusión macroeconómica. En el sistema económico durante la etapa de expansión, el incremento en los beneficios provoca en los agentes una mayor disposición para la aceptación de crédito, lo que compromete una porción creciente de los beneficios brutos esperados, que Minsky denominó renta bruta de capital al servicio de la deuda.

Según Gruić y Wooldridge (2012, p. 3), esta dinámica expone el tejido empresarial a un mayor riesgo, ya que, si los flujos de ingresos resultan ser menores de lo esperado o si se elevan los costes financieros, las empresas podrían no ser capaces de cumplir con los compromisos de pago.

En un sistema económico relativamente estable la existencia de un incremento en el crédito de inversión provoca mayores beneficios a nivel agregado, dado que los beneficios superan continuamente las expectativas. En esta lógica, el servicio de la deuda no es problemático, ya que existe una mayor disposición de las empresas a pedir prestado, pero cuando esta situación de endeudamiento prevalece durante varios años deriva en un cambio repentino en el modo de actuar de los agentes en el sistema, que se traduce en especulación y en la vuelta al sistema inestable: los bancos y los mercados de capitales aumentan el coste de financiación con incrementos en la tasa de interés, lo que reduce la liquidez, como señala el teorema de la HIF. Así, según indica Minsky (1992, p. 7), durante los períodos de prosperidad prolongada las economías transitan de un sistema de relaciones financieras estable a uno en el cual el sistema es inestable. En un período prolongado, las economías capitalistas tienden a pasar de un sistema de unidades financieras, denominadas de cobertura, a uno en el que la estructura predominante son las finanzas especulativas y/o de Ponzi.

En un escenario de inestabilidad financiera, tras el aumento del coste de financiación, la disminución de liquidez y el incremento de la deuda, se puede producir una venta masiva de bonos y acciones, cuyas consecuencias son la caída del precio de los títulos financieros y que los flujos de caja no validen el gasto de inversión pasada. Ello dará lugar a un incumplimiento generalizado de los compromisos previos de deuda, lo que puede ocasionar deflación financiera y recesión económica, según la estructura de la deuda (Levy, 2013, p. 277).

Este tipo de comportamiento en el sistema económico lleva inevitablemente a las situaciones financieras descritas por Minsky (1986, p. 371), en las cuales las unidades de financiación cubierta (UFC) son aquellas en las que el valor capitalizado de las cuasi-rentas ${ }^{2}\left(P K_{i}\right)$ supera al valor capitalizado de los compromisos ( $K(c c i)$ ) para todo $i$, donde $K$ representa una recapitalización que es de la misma proporción en ambos. Es decir, cuando una unidad financiera cubierta pide un crédito, esta tiene un margen de seguridad en el valor de mercado de los activos sobre el valor de mercado de las deudas $\mathrm{y}$, por tanto, o bien se tiene la suficiente capacidad de pago o bien los flujos de caja son suficientes para hacer frente a las obligaciones contratadas en tiempo y forma, dependiendo del funcionamiento normal de los mercados de productos y factores. En consecuencia, en una unidad con financiación cubierta, resulta que $P K i>K(c c i)$.

\footnotetext{
2 Cuasi-renta: valor de los ingresos suplementarios que recibe un factor productivo cuando la oferta de este no puede aumentarse durante un período determinado, casi siempre corto.
} 
Por otra parte, como señala Minsky (1986, p. 373), las unidades de especulación (UFE) son aquellas que tienen compromisos de pago de intereses para algunos períodos -por lo general, a corto plazo- en los que $K(c c i)>P K i$ en mayor proporción de lo esperado. No obstante, en el largo plazo, el valor de $P K i$ será mayor que $K(c c i)$, ya que una vez pagado el principal no hay capacidad de pago futuro para cumplir con las obligaciones contraídas.

El proceso de pago del capital no se realiza a través de flujos de caja debido a que estos no son suficientes y, por ello, o se paga con ingresos de nuevas deudas o bien estas unidades o entidades deben renegociar sus deudas o disponer de algunos de sus activos y, además, dependen de que el conjunto de los mercados financieros funcione con normalidad; esto es, se depende, como en una UFC, de los mercados. En consecuencia, en las unidades con funcionamiento especulativo resulta que $P K i \geq K(c c i)$.

La clave del problema se encuentra en las unidades de financiación Ponzi (UFP), que se producen cuando los ingresos no son suficientes para pagar los intereses, por lo que se requiere más endeudamiento para cubrir este pago. Según Minsky (1986, p. 377), estas unidades no pueden afrontar sus obligaciones con los flujos de caja, $K(c c i)>P K i$, ya que estos flujos no son lo suficientemente grandes como para cubrir la devolución del capital ni para el pago de los intereses, produciéndose una disminución de la liquidez y, por consiguiente, es preciso recurrir a vías alternativas de financiación: la venta de activos (primera vía) o la petición de créditos (segunda vía). Obtener un valor positivo es cuestionable en este tipo de esquema, por lo cual llegar a $P K i>K(c c i)$ depende de un evento favorable para llevar a cabo la financiación.

En las unidades con financiación Ponzi, donde $K(c c i)>P k i$, pasar a $P K i>K(c c i)$ es altamente incierto, pues pueden producirse distintas situaciones: reducción del ingreso, aumento de la tasa de interés, o ambas a la vez.

Minsky propone un ciclo económico con dos escenarios. En el primero de ellos, se pueden tener regímenes de financiación estables debido a que los agentes de financiación cubierta dominan sobre los especulativos y Ponzi, dando lugar a un incremento del crédito y a la disposición para la captación de este, junto con un aumento de los beneficios. El segundo escenario es aquel en que los agentes Ponzi y especulativos superan a los de financiación cubierta, lo que induce a una disminución del crédito, ya que para esas unidades financieras es fundamental obtener créditos para refinanciar su deuda. El funcionamiento de estas unidades se vuelve incierto y los rendimientos que se tenían en un período previo inevitablemente caen o desaparecen. Más grave aún es que el prestamista tiende a reducir sus pérdidas forzando la quiebra.

La Figura 1 ilustra estas dos posibilidades. Inicialmente, se aprecia lo qué sucede en el sistema "estable" con incremento de créditos y de beneficios. En este caso se puede mantener la operación de empresas en cualquier situación financiera debido a la existencia de un flujo continuo de crédito, pero ante el cambio en el comportamiento de los agentes y el incremento en el riesgo, el sistema inevitablemente cae en el denominado "Momento Minsky", que es el momento en el que se produce un colapso repentino de los activos que forman parte del ciclo de crédito o ciclo económico, como consecuencia de largos períodos de prosperidad para pasar, posteriormente, a una situación financiera inestable. En el segundo momento, el sistema se transforma en inestable debido a las decisiones de los agentes, lo que implica la restricción del flujo de créditos, una liquidez insuficiente y, por tanto, un incremento de la brecha de los compromisos de pago en efectivo (deuda). En estas condiciones las unidades económicas se mueven hacia un comportamiento especulativo o incluso Ponzi.

La descripción general de la economía griega que se presenta en el siguiente epígrafe, junto con la explicación teórica de la HIF y la clasificación y explicación del funcionamiento de las unidades financieras, pemite localizar a Grecia en cada uno de estos momentos y en el tipo de posición financiera que le corresponde. La economía griega, al sufrir problemas de financiación y para poder afrontar las obligaciones de esta, tuvo que negociar la asistencia de países de la zona euro y de organismos internacionales.

La lógica de la globalización financiera provocó que los flujos de capital se convirtieran en el motor del funcionamiento de economías grandes o pequeñas, externas o locales, al ofrecer la posibilidad de obtener recursos que financiaran la compra de activos reales o financieros que indujeran a una situa- 
ción de mayor apalancamiento. Esta evolución financiera permitió a Grecia encontrar los recursos que le llevaron hasta el momento Minsky y, posteriormente, a una situación de inestabilidad o de finanzas Ponzi.

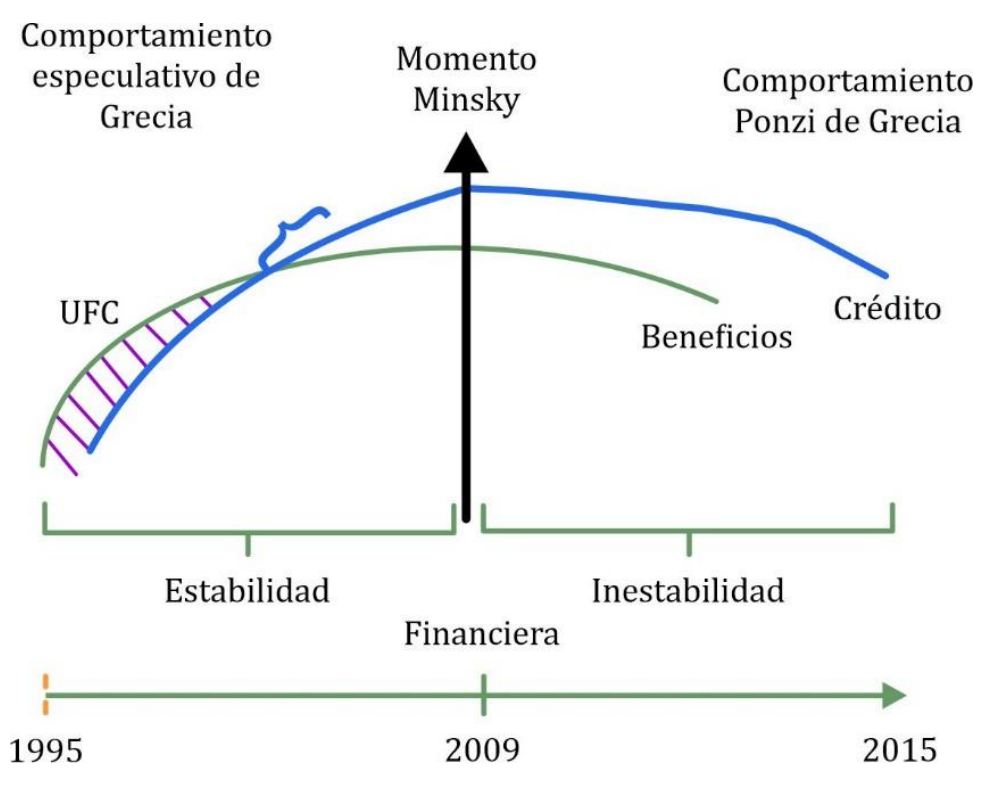

Figura 1. Traslado de un sistema financiero con las diferentes unidades de financiación: el caso de Grecia. Fuente: Elaboración propia a partir de Minsky $(1986,1992)$.

\section{Las consecuencias del endeudamiento}

En el año 2009 estalló la crisis económica griega como consecuencia del aumento del endeudamiento público, que llegó a su nivel más alto con 356 mil millones de euros (MME) en el año 2011, lo cual encendió las alarmas en la zona euro (ZE) y puso en duda la continuidad del proyecto de integración europea. Todo apuntaba hacia un futuro muy complicado en el proyecto más aventajado de integración regional. Para afrontar los efectos de una caída económica y los diferentes problemas de endeudamiento, especialmente en España, Irlanda, Portugal, Chipre y Grecia, se negociaron planes de financiación con el fin de favorecer la liquidez necesaria para cumplir con las obligaciones contratadas (pago de intereses y maduración de contratos de deuda) y la recapitalización de la banca privada.

Las instituciones que proporcionaron el flujo de recursos necesarios fueron el Banco Central Europeo (BCE) y la Comisión Europea, que creó el Fondo Europeo de Estabilidad Financiera (FEEF) y, posteriormente, el Mecanismo Europeo de Estabilidad (MEE). Como indica Tooze (2018, p. 30), el Banco Central Europeo (BCE) junto con los estadounidenses, para impedir que Grecia se convirtiera en otro Lehman, movilizaron al FMI, la creación por antonomasia del globalismo de mediados del siglo XX, para que rescatara a la Europa del siglo XXI.

Las reglas de la operación obligaban, en un primer momento, a que el Gobierno heleno redujera el gasto público, ya que para los organismos internacionales y para los países fuertes de la Unión Europea (UE), especialmente Alemania, el gasto público excesivo era la razón fundamental que había provocado el hundimiento de estos países en la crisis. No obstante, como se muestra en la Figura 2, entre los años 1995 y 2007, el coeficiente deuda/PIB se mantuvo próximo al 100\%, un desequilibrio relativamente manejable, pero a partir de la Gran Recesión ese comportamiento se modificó y derivó en un crecimiento acelerado en el período 2008-2013. 
Transcurridos ocho años desde el primer apoyo financiero y de la ejecución de reformas estructurales demandadas por los prestamistas para impulsar el crecimiento de la economía griega, no aparecen resultados positivos plasmados en una disminución significativa del cociente de deuda pública/PIB, que llegó al 181,1\% en el año 2018, con un valor de $334.573 \mathrm{ME}$, cifra muy superior al tamaño de su economía, cuyo PIB para ese año fue de 184.713 ME. Igualmente, como se puede observar en la Figura 2 , ni el gasto ni el ingreso gubernamentales crecieron significativamente, aunque el déficit aumentó entre los años 2008 y 2013, para después dejar prácticamente de existir al presentar un nivel medio del 1,08\% en el período 2015-2018 y más tarde alcanzar el tope del 15,15\% en el año 2009. Esta reducción del déficit por la vía del gasto permitió a Grecia colocarse en niveles inferiores a otros países de la ZE, como España y Portugal, que registraron déficits públicos, respectivamente, del 5,9\% y del 7,20\% en el año 2015 (Eurostat, 2015).

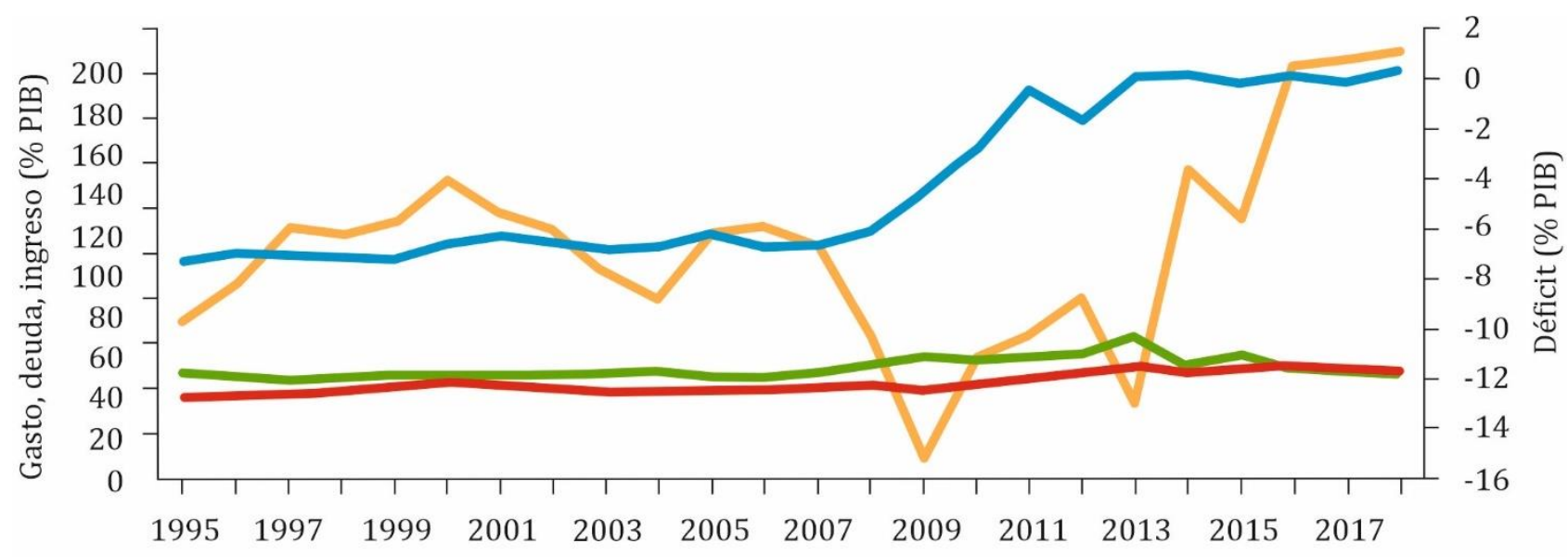

Gasto total Gobierno Deuda consolidada Gobierno Ingreso total Gobierno

Déficit

Figura 2. Indicadores macroeconómicos. Fuente: elaboración propia con datos de Eurostat (https://ec.europa.eu/eurostat/databrowser/view/tec00021/default/table?lang=en ).

Para acceder a los apoyos financieros se impusieron reducciones en el gasto corriente que implicaron un recorte de 150 mil funcionarios que tuvo como reflejo inmediato el incremento del desempleo, que afectó al 25\% de la población económicamente activa (PEA) en el año 2014 y que llegó al 21,5\% en el año 2017, después de un nivel del 7,8\% en los inicios de la crisis del año 2008. El desempleo entre los trabajadores de entre 16 y 24 años tocó techo al llegar a un 60\% (Sánchez Vallejo, 2018, p. 15), y en el año 2016 el 29,4\% de los trabajadores eran autónomos, es decir, estaban en la informalidad (Salvatierra, 2017, p. 37). Este fue el resultado de implementar en el período 2009-2016 uno de los mayores ajustes fiscales que hayan existido, pero "desde que se firmó el tercer programa, el Gobierno de Tsipras ha logrado -de hecho, ha superado- los objetivos fiscales" (Pagoulatos, 2017, p. 66). ). Sin embargo, y a pesar de los programas de apoyo, la deuda continuó creciendo a tasas superiores a las del crecimiento económico.

En resumen, a partir de la GR los desequilibrios modificaron su dinámica en un escenario en el que la deuda creció rápidamente y trajo consigo reducciones del gasto público, caída del empleo y un incremento de precios de los bienes públicos que provocó un efecto abrumador sobre el bienestar. La electricidad sufrió un incremento del 7,9\% en el año 2014, mientras que otros productos energéticos fósiles, como el gas, la gasolina y otros combustibles, alcanzaron un incremento del $6 \%$ en ese mismo año. Esta alza repercutió de modo inmediato en el precio del transporte, que subió un 2,9\%. Entre los años 2009 y 2016 los salarios reales cayeron año tras año a una tasa media de un 3,1\%, mientras que las pensiones fueron recortadas 13 veces, lo que situó a un 36\% de la población en el margen de la po- 
breza y de la exclusión social. Una razón central de este grado de pauperismo es que cerca del 50\% de los hogares griegos dependen de una pensión como principal fuente de ingreso.

\section{La dinámica de la crisis de endeudamiento}

Los desequilibrios de la macroeconomía, como ya hemos apuntado, tienen un amplio sustento en la ruta de reestructuración de la deuda pública que se encontraba colocada con distintos acreedores, y que se vio modificada continua y principalmente por los tres programas de apoyo financiero facilitados desde el año 2010. El FEEF ocupa el primer lugar entre los acreedores de Grecia al facilitar el 61,45\% de la deuda, que suponía 141.9 mil millones de euros. El segundo lugar fue ocupado por agentes privados, que poseían el $15,45 \%$ del total. A continuación, se sitúan los organismos internacionales como el FMI y el BCE, con el 8,95\% y el 7,31\%, respectivamente. Con porcentajes inferiores se encuentran los préstamos bilaterales especiales, con un 2,14\% del total. Después, el Banco de Grecia, con un $1,34 \%$. Y por último, otras entidades no especificadas, con un 3,36\%.

Esta deuda está constituida por dos tipos de pasivos: unos denominados en títulos y otros en préstamos, y que han presentado trayectorias totalmente divergentes desde el año 2009 como consecuencia de la GR. Los préstamos, que predominan sobre los títulos, crecieron hasta representar un 138,8\% del PIB en el año 2015, mientras que los títulos suponían un 33\%, lo que provocó que los pasivos en títulos alcanzaran valores absolutos por un importe de 70.059,07 ME, mientras que los préstamos ascendieron a los 243.285,5 millones en el año 2015.

El difícil panorama del sector productivo y los desequilibrios financieros suscitaron desconfianza en la economía, lo que tuvo como consecuencia una significativa reducción en la precaria -pero existente- inversión extranjera directa (IED), cuyo flujo de entrada se vio reducido desde un $1,61 \%$ del PIB en el año 2008 a tan solo un 0,71\% en el año 2014.

Este escenario de inestabilidad y vulnerabilidad económica situó a Grecia en un camino difícil hacia la recuperación, y dejó al Gobierno de Alexis Tsipras con un bajo margen de acción para resolver diversos problemas como, entre otros, unos altos niveles de endeudamiento público, recesión, unos bajos niveles de inversión o un incremento del desempleo en una dinámica de deflación. La economía griega se encontró en una crisis de deuda-deflación acentuada por la fragilidad financiera del sistema económico mundial, que redujo las fuentes de financiación e incrementó la deuda pública por el excesivo aumento en los costes de su servicio, como se demostrará a continuación en la lógica propuesta por Minsky. En julio de 2017 Grecia obtuvo tres MME en una subasta de bonos a cinco años a una tasa de un 4,6\%, frente al 0,3 que pagaba España. Esta diferencia en el servicio de la deuda generó una carga insostenible para un país con una deuda pública próxima al 180\% del PIB (Doncel y Sánchez Vallejo, 2017, p. 35).

El desarrollo de estos desequilibrios puso sobre la mesa la opción del Grexit, aunque en su gran mayoría la población apoyaba la condición de miembro en la eurozona, a pesar de que, como señala Pagoulatos (2017, p. 66), la persistencia de la austeridad podría hacer menguar este sentimiento. En consecuencia, el descontento creciente de la población, dada la disminución del estado de bienestar social que habían adquirido tras su incorporación a la ZE, provocó manifestaciones populares y enfrentamientos entre la población y el Estado, convirtiendo la crisis económica en una crisis política.

\section{Endeudamiento con estabilidad}

Una vez iniciado el proceso de integración monetaria en el año 1999, Grecia puso en marcha un paquete de herramientas contables para obtener datos fiables que le dieran la oportunidad de incorporarse a la zona del euro (Rozo, 2013; Varoufakis y Tserkezis, 2014). Entre los años 1994 y 2001 Grecia se vio ante la necesidad de hacer converger sus indicadores macroeconómicos con los de otros miembros de la UE, a pesar de la existencia de importantes diferencias en productividad, estructura 
productiva y evolución económica previa a la conformación de la UE, y que hoy en día aún prevalecen entre los países del norte y del sur del continente europeo.

El proceso de aprobación para ser el duodécimo Estado miembro de la ZE fue difícil para el Gobierno debido al retraso de Grecia a la hora de cumplir con los criterios de convergencia ${ }^{3}$ estipulados en el Tratado de Maastricht, del mismo modo que otros condicionantes como la independencia estatal de los poderes políticos nacionales o la prohibición al Banco Central para financiar directamente a la Administración Pública y a las empresas públicas -no a las empresas del sector privado-, lo que supuso una auténtica privatización de las finanzas públicas (Parguez, 2002, p. 4)

Una parte de las complicaciones del proceso tuvo que ver con los diferenciales respecto al resto de los Estados miembros. Su economía se presentaba con un déficit público de un 5,47\% del PIB y una demanda interna elevada, ya que el consumo final de los hogares representaba un $62,2 \%$ del PIB, valor superior respecto de la ZE y de la UE, para quienes suponían, respectivamente, un 56,5\% y un 57,4\%. El consumo de la Administración Pública griega era el más bajo de los doce países: un 14,3\%, frente al $19,8 \%$ de la media EUR-12. El producto por habitante medido en unidades de poder de compra era de 18.865,4 euros, el más bajo de los Estados pertenecientes a la ZE e incluso de la media de dicha zona, donde se situaba en 20.000 euros.

En el período 1995-2000 el ingreso público creció a una tasa media anual de un 8,8\%, mientras que el gasto público lo hizo a un 6,19\%; sin embargo, se mantenía el diferencial entre ingresos y gastos, que tuvo que ser cubierto por medio de deuda, lo que supuso un déficit público equivalente a un $4,05 \%$ del PIB para el año 2000, y una relación de deuda a PIB de un 103,38\%. El hecho sobresaliente en este período previo a su incorporación a la ZE, y después del año 2000, es que Grecia, en términos de déficit y deuda, no cumplió con lo estipulado en los criterios de convergencia. La evidencia muestra que las barreras impuestas por estos criterios para ser miembro de la Unión fueron pasadas por alto. Puede argumentarse que sin la GR el frágil equilibrio pudo ser administrado como se venía haciendo antes de la crisis, al amparo de los flujos de capital.

El gasto público, que se caracterizó por incrementos y bajas tasas de interés, se vio reflejado en el déficit del sector público y, por tanto, en la deuda. En el año 2003 la deuda externa pública equivalía a un 56,19\% del PIB, mientras que la interna llegaba a un 37,71\% como resultado del esfuerzo realizado para disminuir el importe de su deuda. Por su parte, el sector privado incrementó su deuda exterior, pasando de los 62.394 ME en 2003 a los 158.356 ME en el año 2008.

Tras su incorporación a la ZE, el aumento del gasto del Gobierno se vio reflejado principalmente en dos sectores: en el sector de la educación, que pasó de un 7,08\% en el año 2000 a un 9,17\% en el año 2005 como porcentaje del total del gasto; y en el sector de la salud, donde pasó de un $10,12 \%$ a un 13,32\%. No obstante, como argumenta Hernández (2011), en el período previo a las crisis se puso en marcha un modelo económico-social algo costoso. En cierto modo, este modelo económico-social fue una réplica del proyecto con el que había nacido la integración europea, apoyado en uno de los tres ejes baluarte de los valores del liberalismo: la subsidiariedad. El Estado debe trabajar para orientar el bien común, ya que el mercado es incapaz de proveer bienestar a todos los miembros de la sociedad.

En el año 2003 tuvo lugar la conversión al euro (340,75 dracmas por euro) que eliminó, por una parte, la incertidumbre asociada a las fluctuaciones del tipo de cambio $y$, por otra, redujo los costes de transacción generados por diferentes tipos de moneda. De forma paralela, se tuvo el beneficio de un mercado financiero unificado en el que las "bajas tasas de interés permitieron una financiación a bajo coste del déficit de cuenta corriente de países como Grecia..." (Munevar, 2011, p. 7). A pesar de estos desequilibrios, en el momento de entrada a la zona euro el entorno económico griego era de confianza y estaba en auge por las posibilidades del libre intercambio de bienes y servicios, además de la movili-

\footnotetext{
${ }^{3}$ Los criterios de convergencia fueron cuatro: 1) las tasa de inflación no debería superar el 1,5\% de la de los países con menor inflación; 2) el déficit presupuestario no debía de exceder el 3\% del PIB y la deuda pública bruta no debía de pasar el $60 \%$ del PIB; 3) el margen de fluctuación de los tipos de cambio dentro del sistema monetario europeo debería de ser respetado al menos dos años sin devaluaciones ni tensiones; y 4) las tasas de interés a largo plazo no debían exceder más del 2\% de la media de los tres Estados con los mejores resultados en estabilidad de precios (Guillén, 2011, p. 115).
} 
dad de mano de obra entre los Estados miembros. El Gobierno, del mismo modo que la sociedad, confió en la decisión tomada: ser miembros de la Unión Monetaria Europea y aceptar la moneda común.

Para lograr la expansión del gasto público, el Gobierno de Constantino Caramanlis (2004-2009) impulsó diversas reformas tributarias como, entre otras, la disminución de impuestos sobre el capital en un $10 \%$ con el propósito de impulsar la inversión. En el año 2006, no obstante, la brecha de recaudación del impuesto sobre el IVA no cobrado era de un 30\% en comparación con la UE, donde suponía un $12 \%$. A pesar de este bache recaudatorio, en el primer año de su implementación no se registró incremento alguno del déficit ni de la deuda pública pero, como señala Mourenza (2010), durante este Gobierno se contrataron 55.000 funcionarios, contradiciendo así lo prometido por el Gobierno griego a la UE sobre la reducción del funcionariado y que tenía como objetivo reducir la diferencia entre ingresos y gastos públicos. En consecuencia, "según análisis independientes, la tasa de impuestos no pagados era del 11,8\%, lo cual supuso un déficit de recaudación fiscal del 27,8\%. De haberse recaudado estos impuestos, hubieran cubierto casi todo el déficit del año 2009" (Lianos, 2015, p. 83).

En el período 2000-2007 gastos e ingresos, como porcentaje del PIB, se mantenían relativamente estables, aunque los gastos fueron ligeramente mayores que los ingresos, lo que originó un cambio en la tendencia de reducción del déficit, al pasar de un 4\% a un $6 \%$ del PIB. No obstante, ello no influyó significativamente sobre el endeudamiento que sin duda era alto, pero que se mantenía relativamente estable entre los años 1995 y 2007, como se puede observar en la Figura 1.

El crédito al sector privado comenzó a tener tasas de crecimiento positivas a partir del año 2000, mientras que el Gobierno comenzaría a pedir y a obtener créditos solo cinco años después. La tasa de crecimiento del crédito en el período 1999-2008 alcanzó su mayor valor en el año 2005, con un 19,5\%. El crecimiento en estos años se podría denominar de estabilidad financiera, en concordancia con los postulados de Minsky. El incremento del crédito y la facilidad de su obtención son indicios de que el mercado financiero griego se encontraba en una relativa estabilidad, a pesar de comenzar a tener un comportamiento especulativo. Entre los años 1998 y 2007 las rentas nacionales superaron a los créditos obtenidos, y en los años donde esto no sucedía los capitales que entraban permitían solucionar sus gastos tanto en el sector privado como en el público y mantener el cociente de deuda/PIB relativamente estable. El período de bonanza y beneficios sociales llegó hasta el año 2008, cuando el ingreso per cápita alcanzó los 31.700 dólares, el vigésimo quinto más elevado del mundo. No obstante, el crecimiento no redujo la deuda pública, que se mantuvo en niveles superiores a la media de la UE debido al aumento del gasto y a la evasión fiscal.

El comportamiento deudor y deficitario que venía presentando la economía griega en el período precrisis, la forma de endeudamiento y el comportamiento del sector público y del privado permiten caracterizar al país como una unidad financiera especulativa que se encontraba evolucionando en un espacio financiero estable. La situación era especulativa debido a que los ingresos con respecto a las obligaciones contratadas no eran suficientes en ciertos períodos, y por ello era preciso un flujo continuo de capital que, proveniente del exterior, soportara la disparidad entre ingresos y gastos. Había estabilidad en los mercados. Se puede afirmar que los años anteriores a la crisis de las hipotecas de alto riesgo pueden entenderse como un período de estabilidad, que permitía al Gobierno griego conducir la economía con elevados niveles de gasto público, lo cual inevitablemente repercutía sobre el déficit y, por tanto, sobre la deuda, como señala la HIF. El comportamiento eufórico de los agentes financieros, debido al aumento constante de las ganancias y a la disminución del riesgo, generó innovadores paquetes de productos financieros que alimentaron el incremento del crédito. El estado de superávit de los flujos financieros de países como Alemania y Francia creó las condiciones para la concesión de créditos a los países de menor desarrollo.

La IED que llegó a Grecia durante el período de bonanza comenzó a disminuir a partir del año 2008 hasta representar tan solo un $0,18 \%$ del PIB. Ello contribuyó a que el país no pudiera continuar con el estilo de vida adoptado y propició un cambio en su comportamiento financiero, al pasar de una financiación especulativa a una Ponzi. La situación creada por la crisis de las hipotecas basura se unió a los problemas que ya tenía el país en los años anteriores a su incorporación a la ZE. Aunque se trató de 
hacer converger déficit y deuda pública después de su incorporación a la ZE, estos indicadores continuaron siendo altos. Las brechas de deuda y déficit con respecto a los criterios de convergencia tras el estallido de la GR, provocaron que el sistema financiero relativamente estable en el que se encontraba funcionando tras su incorporación a la ZE se convirtiera en inestable.

El nivel de endeudamiento se mantuvo relativamente estable entre los años 2000 y 2008 debido a que la cantidad de intereses abonados a los deudores no influía significativamente sobre la deuda. El efecto conocido como "bola de nieve"4 se presentó, dado que el crecimiento del producto nominal aumentó en ese período a una tasa superior a la tasa de interés implícita, lo que generó un escenario de estabilidad -como menciona Minsky- durante un largo período de tiempo.

\section{Un agente Ponzi frente a la crisis}

Grecia, del mismo modo que los demás países del sur europeo, mostró un claro debilitamiento de la actividad económica como resultado de la Gran Recesión ocasionada por la crisis de las hipotecas de alto riesgo en Estados Unidos a partir del año 2007 y su efecto global (Rozo, 2011). Y ello a pesar de que la tasa de interés de referencia del Banco Central Europeo (BCE) había bajado del 2,5\% en el año 2008 al 1\% en el 2009. En teoría esta disminución de la tasa favorecería el crecimiento económico ya que, al disminuir el coste del crédito, incrementaría la producción, el empleo y, en consecuencia, facilitaría el consumo. La realidad en los países del sur europeo no se ajustó a la teoría. El crecimiento del PIB en el año 2009 cayó un 3,57\% en España; en Portugal, un 2,97\%; en Grecia, se registró una caída de un 4,30\%; y en Irlanda, de un 5,7\% (Eurostat, 2015).

En Grecia la crisis se agudizó en el Gobierno de Yorgos Papandréu (2009-2011), cuando el nivel de deuda pública creció un 12\% en los años 2008 y 2009, la tasa más alta registrada desde su incorporación a la ZE, lo que elevó su nivel hasta el 126,74\% del PIB. De los 301.062 ME adeudados, el 27,51\% correspondían a deuda interna y el $72,48 \%$ a deuda externa. A pesar de que oficialmente Grecia entró en crisis en el año 2009, desde 2006 se produjo un incremento de la deuda alimentado por la tasa de interés que el Gobierno heleno debió de pagar por los préstamos que se le habían otorgado. Dicha tasa comenzó a ser mayor que la tasa de crecimiento del producto nominal y también mayor que la del déficit año a año, propiciando que el ajuste de flujos ${ }^{5}$ fuera positivo durante tres años consecutivos desde 2008 a 2011 y que en este último año alcanzara el $2 \%$ del PIB. La prima de riesgo, esto es, la diferencia que Atenas tuvo que pagar por su deuda, comenzó a subir en octubre de 2009, pasando desde un 4,5\% por los bonos de 10 años hasta un 12,5\% en mayo de 2010, reduciéndose al 7,3\% una vez anunciado el rescate. No obstante, el 27 de abril de 2010 los bonos griegos cayeron al nivel basura cuando se reconoció que la deuda externa era superior al 15\% del PIB y que debía pagar 20.000 MD el 19 de mayo, cantidad de la que no disponía. Grecia, al ser favorecida por los apoyos financieros y por las reestructuraciones de la deuda, experimentó un cambio relevante en la composición de esta y una disminución del déficit público que le permitió obtener un ajuste de flujos del -35,6\% del PIB.

El cambio en las características del endeudamiento fue consecuencia de la cantidad de intereses pagados, que pasó de representar el 5\% del PIB al 15,2\%, su punto máximo, en el año 2009, por un importe de 35.990 ME. Esta tendencia de crecimiento de la deuda pública alertó de inmediato a las agencias calificadoras que, al notar las altas probabilidades de pago del Gobierno, "bajaron su calificación al nivel de $\mathrm{BBB}+$, la peor de la zona euro y situada solo tres peldaños por encima de los llamados bonos basura" (Lois, 2009). La bajada en la calificación fue un obstáculo adicional para el país, al impedirle obtener nuevos flujos de capital externos y al propiciar una salida masiva de activos fijos totales brutos. En consecuencia, las inversiones netas de entrada en el año 2009 solo llegarán a ser supe-

\footnotetext{
${ }^{4}$ Este efecto se presenta cuando la tasa de interés implícita de la deuda es mayor que la tasa de crecimiento del PIB nominal, y es positiva cuando el tipo de interés implícito pagado por el servicio de la deuda gubernamental es mayor que la tasa de crecimiento nominal del PIB (http://ec.europa.eu/economy finance/ameco/HelpHtml/adggi.html)

5 Este ajuste corresponde a la diferencia entre el cambio en el nivel de endeudamiento público y el flujo de déficit/superávit anual.
} 
riores a las de salida en tan solo un 0,9\% del PIB en los dos años siguientes, mientras que las transferencias de capital pagable en ese mismo período alcanzaron el 6,6\% del producto, con una cuantía de 15,631 millones de euros.

Una vez exacerbados los niveles de endeudamiento, el mayor peso del incremento de la deuda gubernamental se debió a la suma de los intereses pagados por concepto de servicio de deuda. En los años 2006 y 2007 la cantidad que se pagó por este concepto alcanzó un crecimiento de un 60\%. El caso contrario ocurría en los años previos a la debacle económica, durante los cuales los intereses no formaban parte esencial de los incrementos de la deuda, como se puede apreciar en la Figura 3.

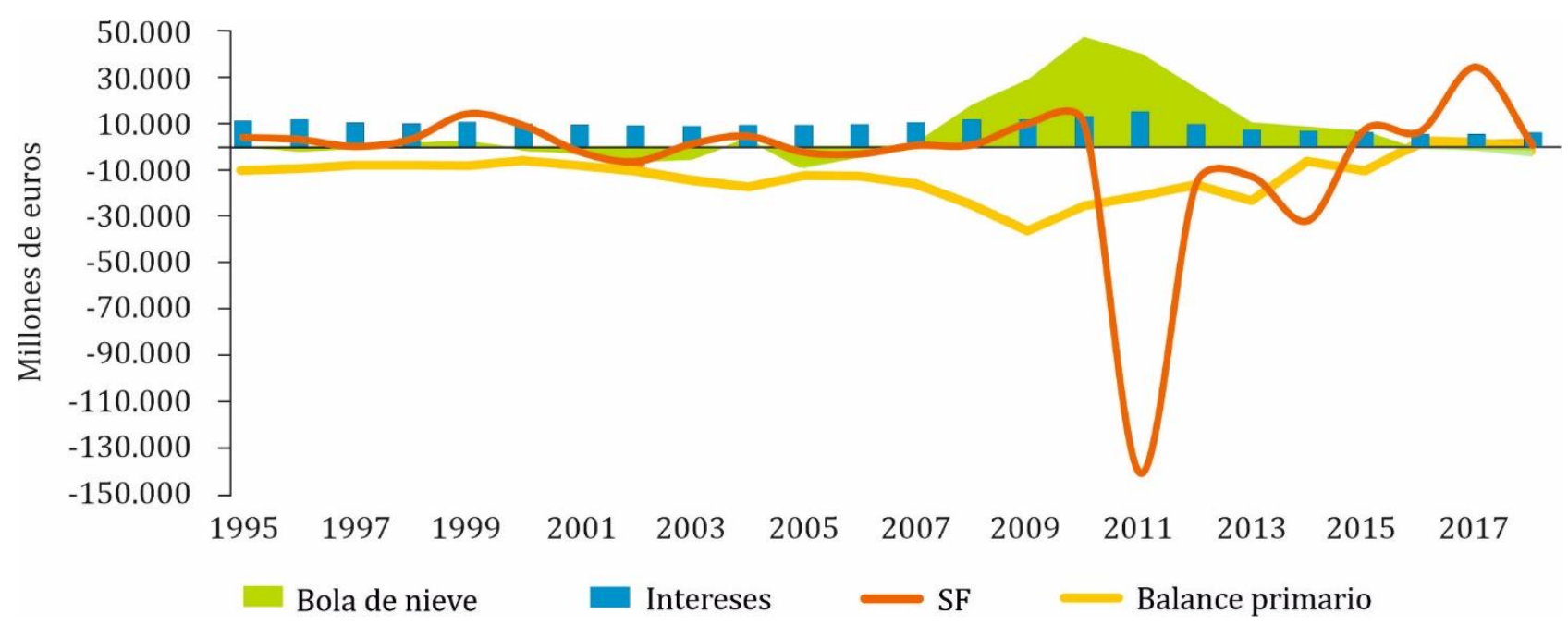

Figura 3. Componentes del incremento de la deuda. Fuente: elaboración propia con datos de AMECO (http://ec.europa.eu/economy finance/ameco/user/serie/selectserie.cfm)

Los altas sumas que pagar, derivadas del servicio de deuda y de la falta de liquidez, obligaron al Gobierno griego a tomar la decisión de emitir obligaciones. En enero de 2010, como indica Mandamadiotou (2013, p. 3), ofreció la cantidad de 8.000 millones de euros en bonos a 5 años. En el mes de marzo lanzó una nueva emisión por un importe de 5.000 millones de euros en bonos a 10 años, recibiendo por ellos un beneficio de cuatro veces esa cantidad. La subasta continuó debido al incremento en los rendimientos, provocando un mayor deterioro del déficit griego.

Igualmente, se optó por diversificar la deuda entre títulos y préstamos de corto y largo plazo, e incrementar la rentabilidad de los bonos. El rendimiento de bonos griegos a 10 años, que desde su incorporación a la ZE pagaban de media un 4,55\%, se elevó drásticamente el 1 de diciembre de 2010 hasta el 12,54\%, y un año después su rendimiento era de un 35,48\%. Estos porcentajes fueron exorbitantes, si consideramos que la tasa de referencia del Banco de la Reserva Federal de EE.UU. se situaba en un 3,28\% en el año 2010, y en el año 2011 había disminuido hasta el 1,87\%.

La emisión de títulos de deuda de largo plazo continuó hasta 2011, año de una abrupta caída de la demanda debido a la falta de confianza de los compradores en la solvencia del país, con la bajada en la calificación de la deuda a BBB+. Los títulos de largo plazo disminuyeron desde el 121,5\% hasta el $38,8 \%$ del PIB entre los años 2011 y 2014 , mientras que los títulos de corto plazo continuaron, y pasaron del 4\% al 8\% en el período 2010-2014 (Figura 4).

La bajada de calificación impuesta por Fitch y Standard \& Poor's obligó al Gobierno griego a una financiación a través de préstamos internacionales para evitar caer en situación de impago o moratoria. Del 100\% del PIB que representaron los préstamos en el año 2006, disminuyeron al $80 \%$ en 2014; mientras, los bonos que alcanzaron el 100\% del PIB en el año 2008 se redujeron al 45\% para el 2014. Era evidente que los recortes del gasto público fueron una medida insuficiente para que Grecia, del 
mismo modo que otros países afectados por la crisis, retomara el rumbo de la estabilidad económica. No obstante, el 11 de febrero de 2010 el Gobierno de Merkel asombró a los mercados al acordar con sus socios la adopción de medidas urgentes para respaldar al euro como tal, pero vetando cualquier oferta de ayuda concreta para Grecia (Tooze, 2018, p. 349).

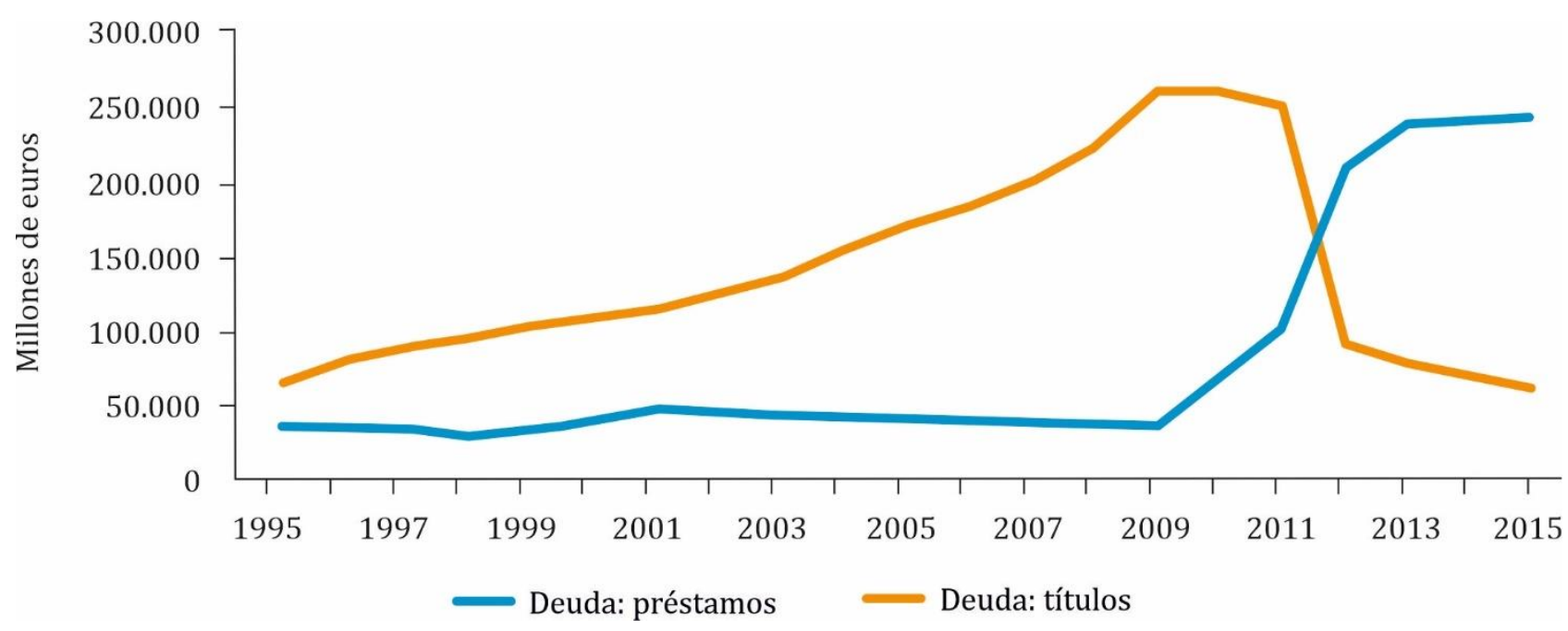

Figura 4. Composición en documentos de deuda. Fuente: elaboración propia con datos de Eurostat (http://appsso.eurostat.ec.europa.eu/nui/setupdownloads.do).

Por tal razón, en mayo de 2010 en el seno de la UE, y en especial en la ZE, se inició un fuerte debate sobre la posibilidad de apoyar con rescates económicos a miembros de la Unión', ya que se ponía en riesgo la continuidad del proyecto de integración. La quiebra de Grecia había golpeado fuertemente a los bancos y fondos de pensiones de Alemania y Francia a los que pertenecía gran parte de la deuda. A finales del año 2010, la exposición de los bancos alemanes en Grecia era de 51 MMD, en tanto que la de los bancos franceses alcanzaba los 111 MMD (Tooze, 2018, p. 347).

No hay que olvidar que en el año 2010 Berlín se negó a la publicación de las pruebas de resistencia de sus bancos para no mostrar el serio deterioro de su sistema financiero, especialmente de las entidades públicas. Alemania atacó la posición de otros países para no mostrar su propia debilidad, ya que una docena de sus bancos habían solicitado ayudas directas a Bruselas, aunque ninguna entidad griega lo hiciera.

El Hypo de Alemania recibió garantías públicas por 95 MME, el Commerzbank recibió capital público por $20 \mathrm{MME}$, pero fueron los bancos de los Länder los que tuvieron los mayores problemas. De hecho, Alemania creó un banco malo para hacerse cargo de activos tóxicos por un importe de 85 MME. También es preciso poner sobre la mesa que la intervención de los especuladores contribuyó a la crisis, como la sospecha de fraudes y de falta de transparencia en los días previos al 10 de mayo, cuando se anunció un paquete por un importe de un billón euros. El Comité Europeo de Reguladores de Activos Financieros (Committee of European Securities Regulators) sospechó de la existencia de manipulación de los precios de los bonos y de las acciones que contribuyeron a la crisis cuando admitieron el 7 de mayo que estaban investigando una "volatilidad excepcional" en los mercados (Misse y Pérez, 2010).

Esta situación llevó a que la canciller Merkel, obviando las objeciones de Francia y del BCE, forzara la intervención del FMI, integrando la impopular troica de la UE, el BCE y el FMI que "dictaría políticas

${ }^{6}$ Adicionalmente, en mayo de 2010 el BCE inició su Programa de Flexibilidad Cuantitativa mediante la compra de bonos de Gobierno, con lo cual el BCE se convirtió en un importante poseedor de deuda griega. Hay que tener en cuenta que este Programa fue una desviación del principio vigente en la eurozona de no rescatar gobiernos por la vía de políticas monetarias. 
a Grecia y a los demás países receptores de ayuda financiera [...] la deuda griega existente se pagaría con nuevos préstamos de la troica, con independencia de si el resultado era sostenible" (Tooze, 2018, p. 356).

Finalmente, el 2 de mayo del 2010 se aplicó un primer programa de ajuste económico para Grecia por un importe de $110.000 \mathrm{ME}$, de los que 80 mil millones serían proporcionados por países de la EZ y 30 mil millones por el FMI. Estas cuantías serían otorgadas en trece tramos a lo largo de tres años, entre mayo de 2010 y junio de 2013. Con este acuerdo se abrió la puerta a la intromisión del FMI en asuntos europeos. Como afirma Guillén (2015, p. 127), hacer invertir al FMI en Europa buscaba recordar a los países rezagados de esa región que, en realidad, más que socios eran periferia, y que deberían someterse a las reglas de los países dominantes.

Este rescate por la UE estuvo compuesto por préstamos bilaterales a siete años de vencimiento medio y a la tasa de interés del Euribor a tres meses más un margen de 200 puntos-base en los tres primeros años. El préstamo del FMI tuvo vencimientos de tres años tres meses a cinco años y un tipo de interés calculado como una media ponderada de tipos de interés de corto plazo americano, inglés, europeo y japonés, más un spread del 3\%, y del 4\% después de tres años (Triana, 2015). Esta financiación fue condicionada a una mayor disminución del gasto gubernamental mediante recortes salariales a los funcionarios, reducción de pensiones y aumento de impuestos a las empresas, así como aumentos del IVA y de los impuestos especiales sobre combustible, alcohol y tabaco. Estas condiciones hicieron que en el año 2011 la tasa de crecimiento del PIB fuera negativa en un 8,7\% y que el déficit público se redujera al 10,24\%. El programa de financiación, que especificaba las fechas de los desembolsos por tramos e importes, en la práctica no se llevó a cabo con exactitud ni en los tiempos marcados ni aún menos en las cantidades establecidas. De los 110 mil millones de euros pactados, solo fueron entregados 73 mil millones, de los que el 72,46\% fue otorgado por los países de la ZE y el 27,54\% por el FMI.

Un segundo rescate llegó el 12 de mayo del 2012, mayoritariamente a cargo del FMI y de los Estados que conforman la ZE, por medio del FEEF. Se pretendía que este fuera por un total de $130 \mathrm{MME}$, pero al final el FEEF apoyó con 133,6 mil millones y el FMI con 8,33 mil millones de euros, obteniendo una suma total de 141,9 MME. El rescate giró en torno a cuatro áreas: restructuración para la sostenibilidad fiscal, salvaguardar la estabilidad financiera, mejorar el crecimiento y la competitividad, y potenciar una moderna Administración estatal pública. El coste fue la imposición, nuevamente, de políticas de austeridad con el objetivo de llevar a una disminución de la brecha fiscal griega por medio de una reducción del gasto de $335 \mathrm{ME}$.

Este segundo rescate, sin embargo, fue utilizado para propósitos distintos como la recapitalización de bancos, la liquidación de pagos retrasados y la financiación del presupuesto público. El Gobierno tampoco llevó a cabo las políticas de austeridad que se había comprometido a impulsar, lo que provocó un efecto negativo para la economía griega que, de nuevo, amenazaba con caer en un escenario de impago. No obstante, las políticas de austeridad que tenían como eje las reducciones del gasto público no cambiaron. La reducción fue de 34.024 millones de euros en el año 2014, lo que representó un $38,5 \%$ menos de lo que se tenía en 2008. Capítulos como Defensa se redujeron en 1,95 puntos porcentuales con respecto al gasto total, pasando del 6,45\% en el año 2008 al 4,5\% en 2014; el gasto por habitante pasó del 16,08\% en el año 2008 al 10,68\% en 2014. La consecuencia fue un incremento del desempleo que en el año 2008 afectó al 6,6\% de la PEA, y para el 2014 al 24,8\%.

En el año 2015 se produce un cambio radical al ser elegido como jefe de Gobierno el candidato del partido de izquierda radical Syriza, Alexis Tsipras, que prometía poner fin a las políticas de austeridad impuestas por los gobiernos anteriores. En febrero de 2015, Tsipras afirmaba que Grecia no necesitaba un nuevo rescate, ya que los niveles de déficit disminuían poco a poco, aunque la deuda no dejaba de acrecentarse, y que su plan de gobierno tenía como objetivo lograr estabilidad para la clase trabajadora y recortar o hacer desaparecer los privilegios de la clase acomodada. No obstante, en agosto de 2015 el Parlamento tuvo que aprobar un nuevo rescate por un valor de $86 \mathrm{MME}$, con un período de gracia de 32 años, y que tenía como finalidad el pago por servicio de la deuda, recapitalizar 
los bancos, cumplir con liquidaciones retrasadas y financiar el presupuesto. El objetivo específico era facilitar a las autoridades el pago de las obligaciones contratadas con agentes públicos y privados, disminuyendo el porcentaje de deuda en manos de acreedores privados y aumentando la deuda soberana.

Otra medida aplicada por parte del Gobierno griego para contrarrestar las salidas de capital fue el llamado "corralito", que consistió fundamentalmente en contener la cantidad de dinero en circulación. Por ejemplo, solo se permitía a los cuentahabientes retirar del cajero 60 euros diarios. Además, la cantidad de dinero que podía llevar consigo un griego hacia el extranjero no podía superar la cifra de 10.000 euros. Por otra parte, las transferencias hacia el extranjero no podían exceder los 10.000 al día para las empresas, o 4.000 euros cada dos meses para los particulares.

Este último rescate fue otorgado con una vigencia de tres años -iniciándose en agosto de 2015 y finalizando en junio de 2018- y con una previsión de ejecución en varios tramos. Desde el inicio del rescate y hasta mediados del año 2016, se otorgaron 28,9 MME, de los cuales 13 mil millones, en efectivo, fueron desembolsados el 20 de agosto para pagar vencimientos de la deuda gubernamental, y 10 mil millones para recapitalizar la banca. El resto de la financiación se entregó en cinco tramos, con cantidades que van desde 1 hasta 7,5 MME.

En el último rescate el Gobierno se vio obligado a vender activos por 50.000 millones de euros para pagar al Mecanismo Europeo de Estabilidad y poder financiar inversión (European Stability Mechanism [ESM], 2015). Los costes que el país heleno tuvo que afrontar en el corto plazo y otros con los que tendrá que lidiar por lo menos hasta 2070 -fecha en la cual se cumplen los plazos para la devolución de los tramos proporcionados- son de una considerable magnitud, y apuntan a una pérdida de soberanía debido a la constante vigilancia del FEEF para el cumplimiento de las reformas estructurales acordadas como seguro para la obtención de los distintos tramos durante la financiación. Las reformas estructurales encaminadas al "crecimiento" se orientaron a la disminución del gasto público y al aumento de impuestos. Estas políticas han afectado directamente al empleo y al crecimiento económico, provocando un panorama poco alentador para la recuperación de la economía griega en el corto plazo.

Esta lógica de rescates ha llevado a imponer una carga de servicio de deuda difícil de sostener en el largo plazo. Desde la incorporación de Grecia a la ZE y hasta el año 2008, la media anual de intereses pagados era de 9.670,88 ME, lo que representaba el 5,36\% del PIB. A partir de la crisis, los pagos se incrementaron hasta alcanzar en el año 2011 los 15.067 millones de euros, lo que equivalió al 7,4\% del PIB, aunque con las reestructuraciones de 2014 y con la disminución de la cuantía de los intereses devengados por el capital la cifra disminuyó hasta los 6.989 millones de euros. Otro desembolso que Grecia estaba obligada a pagar era el de transferencias de capital, que en el mismo período ascendieron hasta los 9.856,77 ME de media anual, equivalente al 5,38\% del PIB. Esta cantidad anual fue creciendo hasta alcanzar su mayor nivel de 28.176 ME en el año 2013, lo que supuso que el 10,74\% del producto nacional tuviera que ser utilizado para el servicio de la deuda. No hay duda sobre los efectos del incremento en el coste de la refinanciación (Varoufakis y Tserkezis, 2014, p. 55).

La evolución de este endeudamiento también implica que los sectores responsables se han modificado a lo largo del tiempo. Entre los años 2003 y 2009, el Gobierno era el principal contratante, al tiempo que las sociedades de depósito iban adquiriendo mayor participación, llegando a tener un lugar significativo en el período 2010-2012 como resultado de las condiciones del primer rescate. No obstante, a partir del segundo rescate el Gobierno se convirtió en el principal responsable del endeudamiento, como se aprecia en la Figura 5.

Además, los apoyos financieros proporcionados a Grecia la obligaron a realizar 15 paquetes de reformas entre los años 2010 y 2018 que, como menciona el Consejo Europeo, incluyen reformas en el sector financiero, en la Administración Pública, en las obligaciones fiscales, en el mercado laboral y de productos, en las pensiones y en el programa de privatizaciones. Según datos del Mecanismo de Estabilidad Europea, Grecia solo ha devuelto a través del Fondo Helénico de Estabilidad Financiera la cantidad de 10,9 millones de euros, con lo que el total de la deuda se sitúa en 130,9 ME. 


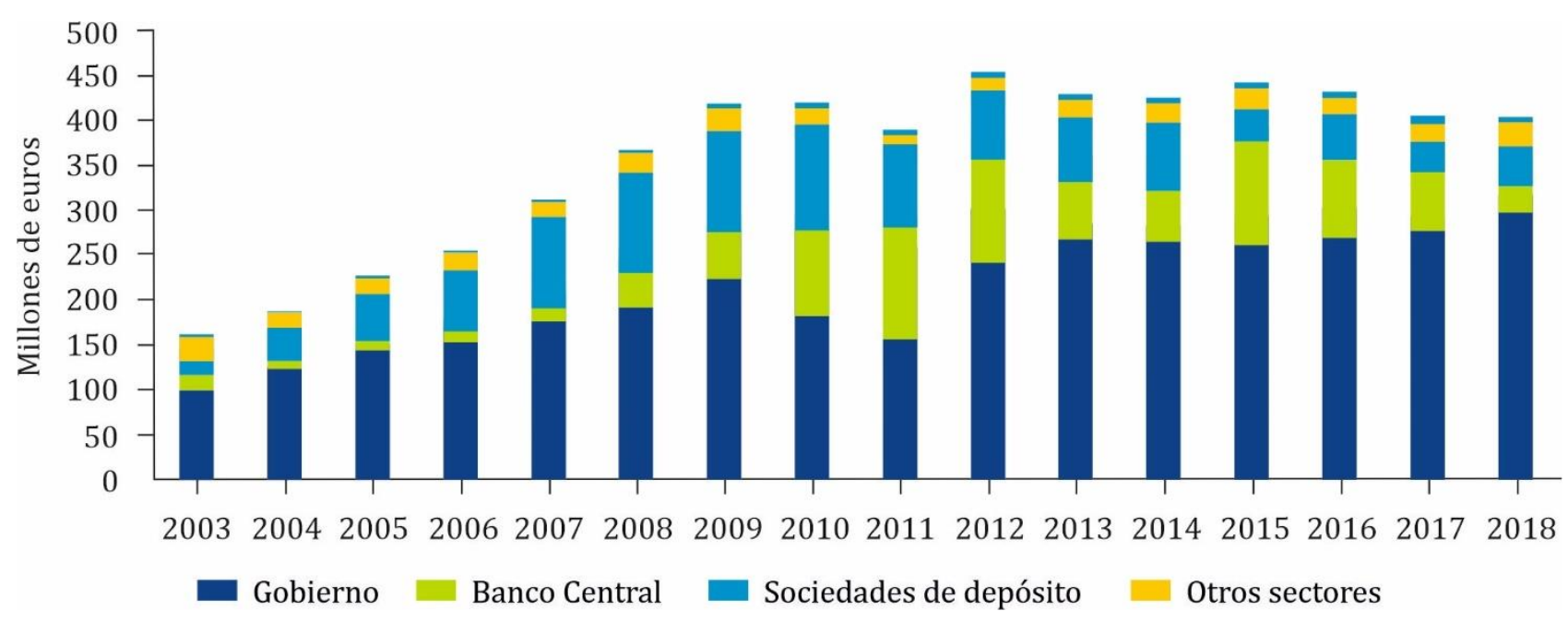

Figura 5. Composición de la deuda griega por sector. Fuente: elaboración propia con datos de Eurostat (http://appsso.eurostat.ec.europa.eu/nui/setupdownloads.do).

Tras diez años en los que la economía griega cayera en estado de crisis, en agosto de 2018 la Comisión Europea dio por terminada la crisis del rescate griego. Desde ese momento, Grecia depende de los mercados para su financiación, lo que supuestamente implica que Atenas retoma la soberanía de su política económica, aunque con múltiples compromisos internacionales nada sencillos de cumplir en términos de reformas y austeridad fiscal. En este sentido hay que considerar que el Gobierno se ha comprometido a mantener un superávit primario del 3,5\% del PIB hasta el año 2022 y superior al 2\% hasta 2060, al tiempo que debe mejorar los salarios, las pensiones y también la sanidad pública. Esta tarea de equilibrio financiero y de estabilidad fiscal parece difícil de administrar y a pesar de que los rescates lograron restaurar el grado de confianza de los inversores y facilitar el derecho de acceso a los mercados financieros, las afectaciones en la estructura productiva y en el bienestar de la población perdurarán por más tiempo.

\section{Conclusiones}

Los problemas de déficit y de endeudamiento de Grecia habían sido controlados en el período previo al año 2008 por medio de los flujos financieros que recibió al convertirse en miembro de la ZE y al hecho de que los intereses pagados por la adquisición de deuda pública se mantenían en una tendencia decreciente respecto al PIB y a que no sumaban incrementos considerables al total de deuda. Estas coyunturas hicieron que a Grecia se le considerase como una economía financieramente estable en la que los agentes de financiación cubierta dominaban sobre los especulativos y Ponzi, con incrementos de crédito y de beneficios, tal y como razona Minsky.

El drama griego posterior a la caída en la inestabilidad financiera tiene raíces en el cambio de características que experimentó su deuda tras la GR. En primer lugar, está la incorporación de Grecia a la ZE, aun cuando no cumplía con los criterios de convergencia establecidos en el Tratado de Maastricht, lo que la convirtió en una economía débil frente a los choques externos y respecto de los restantes miembros de la Unión. También coadyuvó el giro hacia un Estado de bienestar, que obligó al Gobierno a realizar gastos improductivos, como también lo fue la cantidad de facilidades crediticias implícitas en la dinámica de la financiación motivada por su incorporación a la ZE, que inundó el país de importaciones pero que, ante el descontrol financiero posterior, propició fuga de capitales y los problemas de liquidez. Ello obligó al Estado a recurrir a créditos con altas tasas de interés bajo la presión de los acreedores, públicos y privados, que solo pretendieron resarcir su rentabilidad. 
La narrativa anterior apunta a que Grecia, como una entidad especulativa, vivió en un delicado equilibrio financiero en el que solo hacía falta que un choque modificara sus patrones de financiación para poner al país en una situación de impago, como propone la hipótesis de inestabilidad financiera de Minsky. El comportamiento financiero griego muestra claramente como una economía especulativa transita hacia un estado de financiación en el corto plazo y de comportamiento Ponzi, debido a la necesidad de liquidar el servicio de la deuda y del capital prestado en condiciones difíciles para obtener crédito. En el primer escenario se puede concluir que, mientras prevalecieron las condiciones de flujo continuo de capital, Grecia pudo controlar el pago de intereses producidos por las deudas contratadas tras su incorporación a la zona euro. Este estado de relativa estabilidad financiera cambió con la Gran Recesión del año 2008, que causó la crisis hipotecaria inducida por el gran capital transnacional a través de las extravagancias de la financiación y transmitió con violencia sus efectos hacia distintos países, uno de los cuales fue Grecia. El carácter especulativo al que había transitado el sistema financiero estaba incapacitado para hacer frente a la inestabilidad financiera mundial. Los niveles de deuda y de déficit se incrementaron como una bola de nieve ante la necesidad de un mayor apalancamiento a muy altas tasas de interés para cumplir con sus obligaciones de servicio de la deuda, especialmente las que tenía con instituciones privadas.

En el segundo escenario, y una vez que los intereses acumulados no pudieron ser satisfechos a sus acreedores como consecuencia de la parada repentina de los flujos financieros y del pánico generalizado del sistema, vino la bajada en la calificación de la deuda gubernamental, que obligó a las autoridades a transitar por una senda de austeridad. Los gobiernos se vieron forzados a aceptar rescates financieros de organismos europeos e internacionales para afrontar problemas de liquidez y cubrir compromisos de pago, lo que comportó tanto un cambio del tipo de agentes poseedores de documentos de deudas como el tipo de activos con altos niveles de tasas de interés.

Aunque se puede argumentar que a Grecia se le otorgaron las ayudas posibles apegadas al marco regulatorio de la zona monetaria para que pudiera regresar de nuevo al sendero de crecimiento económico, esos importes financieros fueron otorgados bajo unas condiciones que repercutieron severamente en el sector productivo. Las restricciones sobre el gasto corriente para disminuir los niveles de déficit público y, por tanto, la deuda impactaron negativamente en los niveles de empleo y en las pensiones en un escenario de deflación, venta de empresas paraestatales y controles en la retirada de efectivo de los bancos. La práctica de estas políticas de austeridad redujo al mínimo el gasto público y asfixió el mercado interno, lo cual repercutió negativamente en el crecimiento, en el empleo y en la Seguridad Social, y produjo efectos desastrosos sobre el ciudadano común. No ocurrió así con los agentes financieros, como fue el caso de los bancos que fueron apoyados cuando el Gobierno absorbía las deudas.

Sin dejar de reconocer que existió un grado de ineficiencia en el gasto público, es un desatino aseverar que los niveles de deuda que crecieron -y siguen creciendo- fueron causados por los excesos del gasto corriente y del bienestar social porque, aun teniendo un superávit primario de 1,8\% del PIB, Grecia tiene en el año 2018 una deuda superior a la que alcanzó en los años más fuertes de la crisis. Se ha argumentado en este trabajo que el tamaño de la crisis tuvo su principal causa en el nivel del servicio de la deuda, que aumentó significativamente por los intereses en beneficio de los acreedores, y que llevaron a un efecto bola de nieve. La masa total de deuda del país no responde únicamente al dispendio gubernamental -que sí hubo-, sino principalmente al pago del servicio de la deuda en que tuvo que incurrir para que los bancos de los países del norte no tuvieran que afrontar su propia crisis.

\section{Bibliografía}

Blyth, M. (2014). Austeridad. Historia de una idea peligrosa. Barcelona: Crítica.

Doncel, L., y Sánchez Vallejo, M.A. (31 de julio de 2017). Grecia se aleja de la depresión con tibias señales de mejora. El País.

Recuperado de https://elpais.com/economia/2017/07/30/actualidad/1501435168 069215.html 
Drucker, P. F. (1986). The changed world economy. Foreign Affairs, (primavera), pp. 768-791.

European Stability Mechanism (ESM). (2015). ESM proposal for the tranche of E26 billion under the Financial Assistance Facility Agreement for Greece. Recuperado de https://ec.europa.eu/info/sites/info/files/201508-14esmproposalfor1sttranche.pdf

Eurostat. (2015). Eurostat your key to European statistics. Luxembourg, Luxembourg: Eurostat. Recuperado de http://ec.europa.eu/eurostat

Galbraith, J. K. (2007). El crash de 1929. México DF, México: Ariel.

Gruić, B., y Wooldridge, P. (2012). Mejoras en las estadísticas del BPI sobre títulos de deuda. BIS Quarterly Review, (December), 1-15. Recuperado de https://www.bis.org/publ/qtrpdf/r qt1212h_es.pdf

Guillén, A. (2015). La crisis global en su laberinto. México DF, México: Biblioteca Nueva.

Hernández, I. (20 de junio de 2011). El jardín de las delicias griegas. El Mundo. Recuperado de https://www.elmundo.es/elmundo/2011/06/19/internacional/1308472242.html.

Kindleberger, C. P., y Aliber, R. Z. (2011). Manias, panics and crashes: A history of financial crises. London, England: Palgrave Macmillan.

Lapavitsas, C. (2009). El capitalismo financiarizado. Expansión y crisis. Madrid: Maia.

Levy, N. (2013). La evolución de las deudas en México: ¿mayor financiamiento o mayor especulación financiera? En G. Mantey y T. S. López Gónzalez (Eds.), La nueva macroeconomía global distribucion del ingreso, empleo y crecimiento (pp. 273-297). Nezahualcóyotl, México: UNAM, FES Aragón.

Lianos, I. (2015). La crisis del endeudamiento de Grecia. Foreing Affairs Latinoamerica, 15(2), 80-90.

Lois, A. (8 de diciembre de 2009). Standard \& Poor's amenaza con bajar la nota a Grecia. El País. Recuperado de https://elpais.com/diario/2009/12/08/economia/1260226801 850215.html

Mandamadiotou, K. (2013). El carácter de la crisis griega. International Relations Quarterly, 4(1), 1-9. Recuperado de http://www.southeast-europe.org/pdf/13/dke 13 E p Harikleia-K-Mandamadiotou El-caracter-dela\%20crisis-griega Eva-Besleme.pdf.

Menkhoff, L., y Tolksdorf, N. (2001). Financial market drift. Decoupling of the financial sector from the real economy? Berlín, Germany: Springer-Verlag.

Minsky, H. P. (1986). Stabilizing an unstable economy. Annandale-On-Hudson, NY: Levy Economics Institute of Bard College.

Minsky, H. P. (1992). The financial instability hypothesis. Annandale-On-Hudson, NY: Levy Economics Institute of Bard College.

Misse, A., y Pérez, C. (20 de junio de 2010). ¿Por qué Berlín ataca a España? El País. Recuperado de https://elpais.com/diario/2010/06/20/economia/1276984802 850215.html

Mourenza, A. (6 de mayo de 2010). Noticias desde: Grecia. Diario de la crisis griega I: El expulsado. Recuperado de https://noticiasdesdegrecia.wordpress.com/inicio-crisis-2010/

Munevar, D. (2011). Crisis de la deuda en Europa: ¿cerca del colapso? Liège, Belgium: Comité para la Abolición de las Deudas Iletítimas (CADTM). Recuperado de http://www.cadtm.org/Crisis-de-la-Deuda-en-Europa-Cerca

Pagoulatos, G. (2017). Greece: Searching for light at the end of the tunnel. Intereconomics. Review of European Economic Policy, 52(2), 66-67. D0I: https://doi.org/10.1007/s10272-017-0646-y

Parguez, A. (2002). Le modèle européen de l’Union Monétaire: l'harmonisation par l'austérité. Journée d'Études du Centre d'Etudes de la Pensée et les Systèmes Economiques. Grenoble, France.

Rozo, C. A. (2003). Apertura, crecimiento y estructura financiera. El desacoplamiento financiero a la mexicana. En G. Mántey y N. Levy (Coords.), Financiamiento del desarrollo con mercados de dinero y capital globalizados (pp. 207-252). Naucalpan de Juárez, México: UNAM-Acatlan / Ciudad de México, México: MA Porrua.

Rozo, C. A. (2011). Caos en el capitalismo financiero global. Ciudad de México, México: Océano / UAM-México.

Rozo, C. A. (2013). El euro y la doble crisis de la Unión Europea. Matices, 22, 118-138.

Salvatierra, J. (7 de septiembre de 2017). Grecia e Italia, los países de la UE con más autónomos. El País. Recuperado de https://elpais.com/economia/2017/09/06/actualidad/1504708638 758448.html

Sánchez Vallejo, M.A. (29 de abril de 2018). Los ninis forzosos de la crisis en Grecia. El País. Recuperado de https://elpais.com/internacional/2018/04/19/actualidad/1524154571_113071.html

Schularik, M., y Taylor, A. (2012). Credit booms gone bust: Monetary policy, leverage cycles and financial crisis, 1870-2008. American Economic Review, 102(2), 1029-1062. DOI: http://dx.doi.org/10.1257/aer.102.2.1029

Stiglitz, J. E. (3 de junio de 2011). Stiglitz afirma que las políticas de austeridad condenan a los países a la debilidad. El País.

Recuperado de https://elpais.com/economia/2011/06/03/actualidad/1307086382 850215.html

Temin, P. (1991). Lessons from the Great Depression. Cambridge, MA: MIT Press. 
Triana, P. (21 de julio de 2015). Las transferencias a Grecia. El Mundo. Recuperado de https://www.elmundo.es/economia/2015/07/21/55ad2b59ca474140318b458e.html

Tooze, A. (2018). Crash. Cómo una década de crisis financieras ha cambiado el mundo. Barcelona: Crítica.

Varoufakis, Y., y Tserkezis, L. (2014). Financialization and the financial and economic crisis: The case of Greece. Studies in Financial Systems, 25. Financialization, Economy, Society and Sustainable Development (FESSUD). Recuperado de http://fessud.eu/wp-content/uploads/2012/08/FESSUD studies-in-financialsystems Greece final Study25.pdf

Vence, X. (2014). Crisis y fracaso de la Unión Europea neoliberal: una alternativa soberanista y democrática. Madrid: Eneida.

Zettelmayer, J., Avgouleas, E., Eichengreen, B., Poiares Maduro, M., Panizza, U., Portes, R., Wedwe di Mauro, B., y Wyplosz, C. (2018). How to solve the Greek debt problem. Peterson Institute for International Economics Policy Brief. Washington DC, WA: Peterson Institute for International Economics.

Recuperado de https://www.piie.com/system/files/documents/pb18-10.pdf 